\title{
Job Insecurity Research is Still Alive and Kicking Twenty Years Later: A Commentary
}

\author{
Wilmar B Schaufeli ${ }^{1,2}$ \\ ${ }^{1}$ Research Unit Occupational and Organizational Psychology and Professional Learning, University of Leuven, ${ }^{2}$ Department of Psychology, Utrecht University
}

\begin{abstract}
This paper comments on the review of longitudinal job insecurity studies in this special issue. The main conclusion of that review, namely that job insecurity leads to poor health and well-being, remains undisputed. It is argued, however, that future job insecurity research should focus more on: (a) uncovering the underlying psychological mechanisms of job insecurity; (b) the effects of new forms of labor contracts; (c) differences across nations as a function of different social security systems; and (d) the effects of organisations. It is concluded that job insecurity is a problem of our time and that 20 years after the publication of Dekker and Schaufeli's study on job insecurity among workers in Australian public transport corporation, psychological job insecurity research is still alive and kicking.
\end{abstract}

Key words: Australia; burnout; job insecurity.

\section{The Original Study}

"There is so much change going on nowadays, we don't know what is going to happen to our jobs. They treat us like mushrooms, keep us in the dark and feed us with nothing but bullshit." Twenty years ago we started our paper on the effects of job insecurity on psychological health and withdrawal with this quote from an Australian railway signalman (Dekker \& Schaufeli, 1995, p. 57). This quote still illustrates the essence of the experience of job insecurity: uncertainty, powerlessness, and feeling abandoned. By keeping people in the dark, they have no idea of what to cope with and they cannot do anything pending their uncertain job situation.

In our 1995 article, we showed that job insecurity leads to psychological distress and burnout, as well as to mental withdrawal from the organisation. Sidney Dekker-at that time my MA student at Nijmegen University (The Netherlands) and currently a professor and best-selling author on human factors and safety at Griffith University in Brisbane-was very lucky to have the opportunity to conduct, what was to become, a rather unique quasi-experimental study on job insecurity. The study compared a continuously job insecure control group-across time-with an "axe fell" group that was shed off between baseline measurement and a 2-month follow-up. Four "brittle" departments of an Australian public transport corporation participated in the study, two of which closed down during the study period and their staff was laid off, whereas both other departments continued to operate but still under the threat of closing down; their staff was further "kept in the dark." Surplus

Correspondence: Wilmar B. Schaufeli, Department of Psychology, Utrecht University, PO Box 80.140, 3508 TC Utrecht, The Netherlands. Fax: +31 30 253 9093; email: w.schaufeli@uu.nl

Accepted for publication 11 November 2015

doi:10.1111/ap.12201 staff of both closed departments were either reemployed in other public service jobs within or sent home with redundancy payments. In both cases they did not suffer any income loss. Moreover, the study was "double blind" in the sense that neither the researchers nor the employees knew in advance where the axe would fall. So taken together, thanks to sheer luck (for the researchers, not so much for the staff) and the negotiation skills of the union that guaranteed reemployment and prevented income loss (lucky for both the staff and the researchers) we ended up with a unique longitudinal study design. The study was blind as far as the distribution of staff across the control group and "axe fell" group was concerned and the potentially contaminating impact of income loss on psychological health was eliminated. I guess that this uniqueness that allowed us to conclude that the security of actual job loss has less detrimental psychological effects compared with continued job insecurity is responsible for the fact that our study ranks among the most often cited articles of the Australian Psychologist.

\section{Job Insecurity, a Problem of Our Time}

After 20 years, job insecurity is still a major issue, perhaps even more so. For instance, in a recent policy document, the European Union (2013) identifies job insecurity as a "main psychosocial hazard" (p. 13) that is expected to increase in the near future not only because of economic hardship and stringency, but also because of globalisation and increased competition. An indication is that in all $27 \mathrm{EU}$ countries fix-term contracts have increased among new hires from 2006 to 2012, except in Sweden and Finland. The increase was strongest for Ireland with over 20\% (OECD, 2015). As Lübke and Erlinghafen (2014) showed this change in labour contract corresponds with experienced job insecurity, which increased most in Ireland.

So it makes perfect sense that Anonymous (2016) were invited to write an updated review of longitudinal studies on the impact of job insecurity on health and well-being. Their review focuses 
on three issues: (a) an overview of theories that are used to explain the negative consequences of job insecurity; (b) a systemic overview of research evidence on the causal direction of job insecurity, on the one hand, and health and well-being, on the other; and (c) an overview of research gaps in covering specific variables. The results of the review are quite straightforward: (a) a limited number of theories are used, typically as general heuristic frameworks rather than as research models that are tested as such, so in fact most job insecurity research is a-theoretical in nature; (b) the empirical evidence is strongly in favour of normal causation, meaning that job insecurity leads to poor health and well-being instead of the other way around, so in fact job insecurity acts as a job stressor that causes negative effects; and (c) most research included general indicators of health and well-being instead of work-related indicators (e.g., job satisfaction, job burnout, work engagement), or healthrelated behaviours (e.g., alcohol consumption, smoking, medical consumption), meaning that future job insecurity research should be more contextualised and behaviour based.

It is difficult to disagree with the conclusions from the review because they are based on quite compelling evidence. So rather than criticising the review itself, I would like to make some additional comments in order to put research on the psychological consequences of job insecurity is a somewhat wider perspective, thereby suggesting further avenues for future research. I will address four issues: (a) theory-guided job insecurity research; (b) job insecurity and new types of labour contracts; (c) job insecurity across nations; and (d) individual and organisational consequences of job insecurity.

\section{The Underlying Psychological Mechanisms of Job Insecurity}

Job insecurity is defined as the subjective experience of being threatened by job loss (see Anonymous, 2016). Hence, it is by definition a psychological phenomenon, which means that in order to understand it we should look for the underlying psychological mechanisms. In fact, this is also one of the five suggestions of Anonymous (2016) for theory development in the field. But in contrast to them, I would make it a top priority. Rather than defining sizes of time lags, testing existing theories, building an overarching theory, and setting up interdisciplinary studies - the other four suggestions-it seems more urgent to me to clarify the explanatory path from job insecurity to individual (and organisational-see below) outcomes. In its turn, this may constitute the basis for an overarching theory as well as for interdisciplinary research, not only with the medical sciences but also with management and economics. But first things first.

Uncovering the "missing link" between job insecurity and its negative individual outcomes boils down to identifying the most potent mediating processes. As suggested by Anonymous (2016) a possible candidate is psychological contract breach. However, recent studies suggest that other mediating processes may exist as well. For instance, Vander Elst, De Cuyper, Baillien, Niesen, and De Witte (2014) showed that, in addition to contract breach, also loss of control mediated the relationship between job insecurity, on the one hand, and various indicators of job strain and coping, on the other hand. In a similar vein, Van den Broeck, Sulea, Vander Elst, Fischmann, Iliescu and De Witte
(2014) showed that thwarted psychological needs (autonomy, belongingness, and competence) mediated the relationship between job insecurity and counterproductive work behaviour.

The common psychological denominator of job insecurity seems to be that the loss of identity-relevant resources is anticipated, such as control and need satisfaction. Investigating this process of resource loss, including differential effects for different outcomes and different types of persons, should have priority over research that demonstrates, once more, that job insecurity has negative consequences for the individual. This we know already as the review of Anonymous (2016) convincingly demonstrates.

\section{New Forms of Labour Contracts}

At the time when psychological research on employment started in the early 80s full-time, permanent labour contracts were the rule and job insecurity arose when this, often long-term, contract was threatened to be discontinued. Meanwhile, the landscape of labour contracts had diversified and also includes part-time contracts, free-lance contracts, zero hour or casual contracts, temporary contracts-either through an agency or an employer-apprenticeship contracts, and volunteer contracts. As can be expected, survey data from the OECD Employment Outlook (2014) show that employee's perceived risk of job loss is lowest in permanent jobs, followed by self-employment, fixedterm jobs, and temporary agency work, respectively. This agrees with the fact that levels of control and predictability vary with the type of contract, whereby permanent contracts are the most and temporary agency work is the least stable and predictable. That would mean that job insecurity means different things depending on the type of labour contract involved. For instance, using the notion of psychological contract, De Cuyper and De Witte (2008) argued that levels of job satisfaction of temporary workers facing job insecurity would remain stable, whereas job satisfaction would decrease in case of job insecurity among those with permanent jobs. The reason is that job security is included as a basic promise in the psychological contract of permanents, while it is not promised to temporaries. Hence, job insecurity is more detrimental for the former as compared with the latter. But what about the other types of contracts and other outcome measures?

Psychological research on job insecurity should focus more explicitly on people with different types of labour contracts. In addition, most studies used a subjective measure of job insecurity without linking this explicitly to the individual's type of labour contract. By doing so not only the effects of a subjective of job insecurity but also its relation with objective insecurity (i.e., the likelihood of contract termination) can be assessed. The current socio-economic development of diversification of types of labour contracts offers an excellent opportunity for such research.

\section{Job Insecurity Across Nations}

Tellingly, the summary table of longitudinal studies of Anonymous (2016) is heavily biased towards countries with an elaborate social security system that provides the unemployed with relatively generous pensions, although due to the financial crisis these have been cut in most countries. More than $45 \%$ of the studies in the table originate from Scandinavia and the low 
countries (Holland and Belgium), against only $16 \%$ from countries with less abundant social security systems, such as the USA and China. Notably, most studies (i.e., 10) come from Finland, a relatively small country with only 5.4 million inhabitants, whereas only seven come from the much larger USA, with 221.7 million inhabitants. In other words, relative to its number of inhabitants Finland produced 58 times more studies on the individual impact of job insecurity than the USA. The reason for this bias towards countries with advanced social security systems is that in these countries unemployment-and hence also the threat of unemployment that goes with it-is a societal problem in the sense that collectively employees and employers pay its costs via mandatory payments in social security funds.

Unfortunately, the summary table of Anonymous (2016) does not allow drawing any conclusions about cross-national differences in individual impact of job insecurity. Yet, it would be interesting to know to what extent the individual consequences of job insecurity for health and well-being differ between countries, not only regarding differences social security systems but also regarding rates of reemployment. It can be hypothesised that in countries with less advanced social security systems and/or lower rates of reemployment the individual consequences of job insecurity will be more serious. The reason for that would be that the anticipated loss of (financial) resources is larger and/or the likelihood of remaining longer without a job is higher. Some preliminary evidence for the buffering effect of the national safety net is found by Debus, Probst, König, and Kleinmann (2012); compared with countries with a low safety net, job insecurity deteriorates job attitudes (satisfaction and commitment) less than in countries with a low safety net. This kind of interdisciplinary cross-national research calls for collaboration with economists and labour market experts.

\section{Beyond the Individual Consequences of Job Insecurity}

Finally, it is important to go beyond the individual consequences of unemployment and also include the consequences for the organisation. A meta-analysis of Cheng and Chan (2008) showed job insecurity is related to lack of trust in management, poor loyalty, low organisational commitment, high turnover intention, and last but not least poor performance. In addition, it is also related to counterproductive work behaviour, as we have seen earlier. In other words, job insecurity is not only detrimental for the individual employee but it also affects the organisation, even after the lay-off. This is exemplified by the "survivor syndrome" of the workers who kept their jobs after a downsizing process (Appelbaum, Delage, Labib, \& Gault, 1997). The survivor syndrome is characterised by higher anxiety and stress levels, lack of motivation and commitment, general dissatisfaction with working conditions, and distrust towards the organisation. In other words, the health and well-being consequences of job insecurity are highly similar to that of the survivor syndrome.

The Job Demands Resources (JD-R) model (Schaufeli \& Taris, 2014) may constitute a conceptual framework to integrate job insecurity as a job demand (i.e., stressor) and study its simulations effect on effect on individual well-being and organisational outcomes. For instance, using the JD-R model, Hu and Schaufeli
(2011) found in a Chinese sample that job insecurity had a direct as well as an indirect effect, through burnout, on organisational outcomes (i.e., commitment and turnover intentions).

\section{Final Note}

Although job insecurity is by definition a psychological problem, its solution is not. The study of Dekker and Schaufeli (1995) also showed another result, which is not so much cited as the negative impact of job insecurity on psychological health; namely that neither support from colleagues, nor management, nor unions seemed to protect job incumbents from the negative effects of job insecurity. In other words, the social environment does not seem to have a stress-buffering effect. For that reason we concluded in 1995 (p. 57) that “... in order to combat the adverse effects of job insecurity on psychological health an morale, the stressor itself has to be dealt with, instead of trying to render it harmful by providing more social support." This still seems to be the case 20 years later.

\section{Acknowledgement}

Authoring this paper was funded by the Research Fund KU Leuven.

\section{References}

Appelbaum, S. H., Delage, C., Labib, N., \& Gault, G. (1997). The survivor syndrome: Aftermath of downsizing. Career Development International, 6, 278-286. http://dx.doi.org/10.1108/13620439710178639

Anonymous (2016). Review of 30 years of longitudinal studies on the association between job insecurity and health and well-being. Is there causal evidence? Australian Psychologist.

Cheng, G. H. L., \& Chan, D. K. S. (2008). Who suffers more from job insecurity? A meta-analytic review. Applied Psychology: An International Review, 57, 272-303. doi:10.1111/j.1464-0597.2007.00312.x

De Cuyper, N., \& De Witte, H. (2008). Job insecurity and employability among temporary workers: A theoretical approach based on the psychological contract. In K. Näswall, J. Hellgren, \& M. Sverke (Eds.), The individual in the changing working life (pp. 88-107). Cambridge: Cambridge University Press.

Debus, M. E., Probst, T. M., König, C. J., \& Kleinmann, M. (2012). Catch me if I fall! Enacted uncertainty avoidance and the social safety net as country-level moderators in the job insecurity-job attitudes link. Journal of Applied Psychology, 97, 690-698. http://dx.doi.org/10.1037/a0027832

Dekker, W. A., \& Schaufeli, W. B. (1995). The effects of job insecurity on psychological health and withdrawal: A longitudinal study. Australian Psychologist, 30, 57-63. doi:10.1080/00050069508259607

European Union (2013). Occupational health concerns: stress related and psychological problems associated with work. Brussels: Directorate-General for Internal Policies.

Hu, Q., \& Schaufeli, W. B. (2011). Job insecurity and remuneration in Chinese family-owned business workers. Career Development International, 16, 6-19. doi:org/10.1108/13620431111107784

Lübke, C., \& Erlinghafen, M. (2014). Self-perceived job insecurity across Europe over time: Does changing context matter? Journal of European Social Policy, 24, 319-336. doi:10.1177/0958928714538215

OECD (2015). Employment outlook 2014. doi:10.1787/empl_outlook-2014-graph46-en 
Schaufeli, W. B., \& Taris, T. W. (2014). A critical review of the Job Demands-Resources Model: Implications for improving work and health. In G. Bauer \& O. Hämmig (Eds.), Bridging occupational, organizational and public health: A transdisciplinary approach (pp. 43-68). Dordrecht: Springer.

Van den Broeck, A., Sulea, C., Vander Elst, T., Fischmann, G., Iliescu, D., \& De Witte, H. (2014). The mediating role of psychological needs in the relation between qualitative job insecurity and counterproductive work behavior. Career Development International, 19, 525-547. doi:org/10.1108/CDI-05-2013-0063

Vander Elst, T., De Cuyper, N., Baillien, E., Niesen, W., \& De Witte, H. (2014). Perceived control and psychological contract breach as explanations of the relationships between job Insecurity, job strain and coping reactions: Towards a theoretical integration. Stress \& Health. doi:10.1002/smi.2584 